\title{
Association between physical activity and general health in teachers of the universities of medical sciences of Fars Province
}

\section{Asociación entre actividad física y salud general en profesores de las universidades de ciencias médicas de la Provincia de Fars}

\author{
Saeed Sobhanian ${ }^{1}$, Ebrahim Khoshnam ${ }^{1 *}$, Masoud Naderian ${ }^{2}$, and Hosein Dast Barhagh ${ }^{1}$ \\ 1 Department of Physical Education, Jahrom Branch, Islamic Azad University, Jahrom (Iran). \\ 2 Department of Physical Education, Isfahan University, Isfahan (Iran).
}

\begin{abstract}
The aim of this study was to examine the association between physical activity and general health in faculty members of the Universities of Medical Sciences of Fars (Iran). The sample of this cross-sectional analytical study was composed of 244 faculty members of the Universities of Medical Sciences of Fars (Iran) in 2018. The data collection instrument included a three-section questionnaire: 1) Demographic characteristics (age, gender, and household income). 2) Short questionnaire for the measurement of habitual physical activity in epidemiological studies. 3) Goldberg General Health Questionnaire. Data analysis was performed using SPSS 16. The results showed that there was no significant statistical relationship between physical activity and general health subscales in the sample studied. Future studies about this topic with larger samples and in other regions are recommended.

Keywords: physical activity, general health, teachers, university.
\end{abstract}

Resumen: El objetivo de este estudio fue examinar la asociación entre actividad física y salud general en profesores de las universidades de ciencias médicas de Fars (Irán). La muestra de este estudio analítico transversal estuvo compuesta por 244 profesores de las universidades de ciencias médicas de Fars (Irán) en 2018. El instrumento de recopilación de datos incluyó un cuestionario de tres secciones: 1) Características demográficas (edad, género e ingresos del hogar). 2) Cuestionario breve para la medición de la actividad física habitual en estudios epidemiológicos. 3) Cuestionario de salud general de Goldberg. El análisis de los datos se realizó con SPSS 16. Los resultados mostraron que no había relación estadística significativa entre la actividad física y las subescalas de salud general en la muestra estudiada. Se recomiendan estudios futuros sobre este tema con muestras más grandes y en otras regiones.

Palabras clave: actividad física, salud general, profesores, universidad.

\section{Introduction}

Health is one of the basic needs of man (Chhea, Warren \& Manderson, 2010) and plays a vital role in the sustainable development of societies (Safair \& Fattahzadeh, 2003). The World Health Organization (WHO) estimates that the magnitude of behavioral and psychological problems in developing countries is rising and that the phenomenon is largely driven by population growth and rapid social changes such as the breakdown of extended families, urbanization, lifestyle changes and economic problems (Yaghubi, 1995). The World Health Organization defines health as a state of complete physical, mental and social well-being, not just lack of disease or organ failure (Alavi, Ahmadi, \& Zar, 2018). Human health depends on many factors such as heredity, physical activity, living environment, personal patterns and habits, medical care, and family, cultural, economic, and social backgrounds (Ramazani Negad, Niazi, \& Hemati Nezhad, 2010). Karimian and Shokrchizadeh (2007) state that the role of physical activity on mental and physical health is highly important as a factor in human development and progress.

Exercise refers to all forms of physical activity that people

Dirección para correspondencia [Correspondence address]: Ebrahim Khoshnam. E-mail: Khoshnam@Aftermail.Ir can do on a regular, organized or occasional basis, in order to improve their fitness or to provide entertainment and recreation (Watt, 2003). Exercise helps to increase well-being and social adjustment (Alamdari, \& Abdi, 2019; López et al., 2019; Sánchez, López, Sgroi, \& Díaz, 2019). It can also improve the level of dignity, self-esteem, and self-efficacy (Bigdeli \& KaramZadeh, 2006; Esfahani, 2002). Physical fitness exercises can have a positive impact on the treatment of the patients with symptoms of depression and increase their emotional and behavioral responses (Asci, 2003; Voderholzer et al., 2011). Insufficient physical activity and sedentary lifestyle is the cause of $20 \%$ of deaths from cardiovascular diseases, cancer and diabetes. Physical activity is an important factor in reducing mortality and increasing longevity (Brill, 2004, Sharifirad, Mohebbi \& Matlabi, 2007). In fact, regular exercise can increase life satisfaction, quality of life and health (González, Nicolás, \& López, 2020; Nicolás, González, \& López, 2020; Sánchez, Cepeda, Díaz, Smith, \& López, 2019; Sánchez, Zauder, \& López, 2019). Generally, motor ability increases vitality (Garatachea et al., 2009). Gillison, Skevington, Sato, Standage, \& Evangelidou (2009) explain that physical activity has a positive impact on both physical and psychological quality of life domains. Despite the results 
of various researches on the benefits of exercise and physical activity on physical and mental health, the relationship between them is still not clear.

Nowadays, the psychological and physical dimensions of exercise attract the attention of many researchers. Public health has been assessed in all aspects of life, focusing on occupational health and on desirable efficiency of work in organizations that are associated with maintaining and promoting the health of the workers (human resources). In this regard, university professors are considered the most important part of human resources of universities. They are supposed to maintain and promote health in order to achieve more desirable efficiency in transferring knowledge to their students (Solhjoo, Afroozeh, Afroozeh \& Kargar, 2011). Improving the efficiency and productivity of the university faculty staff requires their mental and physical well-being and vitality.

Due to full-time teaching during the week and educational, administrative, economic problems and the conditions dominating the work environment of the faculty, most of the university faculty members are far below their scientific and research capability. This situation probably originates from an inappropriate working environment in Iran universities and it might provoke job dissatisfaction. It can also have a negative impact on the academic teachers' lives and may expose them to mental and physical problems and, in consequence, they may have a harmful influence on the generation under their education (Hashemi et al, 2011). It can be assumed that regular physical activity could solve the problems connected with the health of the academic staff and, based on this assumption, the aim of this study was to investigate the association between physical activity and general health among faculty members of the universities of medical sciences of Fars Province.

\section{Methods}

\subsection{Participants}

The sample of this cross-sectional analytical study was composed of 244 faculty members of the Universities of Medical Sciences of Fars (Iran). Sampling was carried out through stratified random method. Ethics approval was obtained from the Ethics Committee of Jahrom University of Medical Sciences (IR.JUMS.REC.2017.149).

\subsection{Instruments}

The data collection instrument included a three-section questionnaire:
1) The first section contained three questions about the demographic characteristics of the subjects under study, including age, gender, and household income.

2) The second section included the short questionnaire for the measurement of habitual physical activity in epidemiological studies (Baecke, Burema, \& Frijters, 1982). This questionnaire was designed to record physical activity over the last twelve months, and it has three factors: 1) physical activity at work; 2) sport during leisure time; and 3) physical activity during leisure time excluding sport. The validity and reliability of this questionnaire were also investigated in a study of 26 physical education students in the city of Sao Paulo (Brazil), obtaining an internal consistency coefficient of 0.77 (Florindo \& Latorre, 2003). The validity and reliability of this questionnaire has been repeatedly assessed and verified in different countries, as well as in Iran with different groups (Sadeghisani, Manshadi, Azimi, \& Montazeri, 2016).

3) The third section included the Goldberg General Health Questionnaire (Goldberg, 1988). It is composed of 28 items, with 4 sub-scales of 7 questions. There is a score for each subscale and a general health score. The 4 sub-scales are: Physical Symptoms Scale, Anxiety Symptoms and Sleep Disorders Scale, Social Function Scale, and Depression Symptom Scale. The reliability of the split-half method for this questionnaire, completed by 835 individuals, was 0.95 (Goldberg, 1988). In the study of Taghavi, with three tests carried out in Iran, the reliability coefficients of this instrument were $0.93,0.70$ and 0.90 (Taghavi, 2001).

\section{Data analysis}

Data were analyzed through software SPSS 16. Descriptive statistics included mean, standard deviation and frequency distribution. Pearson correlation test was also used to evaluate the correlation between physical activity and general health (subscales and total general health score).

\section{Results}

A total of 133 out of 244 participants were males and 111 were females. The mean and standard deviation of age of the sample was $39.84 \pm 6.58$ years. The mean and standard deviation of income were $6270000 \pm 2870000$ Iranian Toman per month (equivalent to 1881 USD \pm 861 USD). The mean and standard deviation of the main research variables are presented in Table 1. 
Table 1. Central and dispersion indexes of the main research variables.

\begin{tabular}{lcccc}
\hline Variables & Mean & SD & Max value & Min Value \\
\hline Physical activity & 2.8822 & .60748 & 4.75 & 1.50 \\
General health score & 16.9016 & 4.94232 & 39.00 & 7.00 \\
Physical Symptoms Scale & 5.1107 & 3.18692 & 21.00 & .00 \\
Anxiety Symptoms and Sleep Disorder Scale & 3.4795 & 2.23413 & 12.00 & .00 \\
Symptoms of Social Function Scale & 5.1762 & 2.47741 & 18.00 & 2.00 \\
Depression Symptom Scale & 3.1762 & 1.31691 & 10.00 & .00 \\
\hline
\end{tabular}

No significant correlation was found between physical activity and age and income. In addition, there was no significant correlation between gender and general health levels and its subscales, except for the physical symptoms subscale with gender (Table 2). Chi-square test was used to examine this correlation (chi-square: 8.34, df: 1, p-value: 0.003).

Table 2. Frequency of gender by physical health area of general health

\begin{tabular}{lcccc}
\hline General health & \multicolumn{2}{c}{ Healthy } & \multicolumn{2}{c}{ Sick } \\
\cline { 2 - 5 } & Frequency & Percent & Frequency & Percent \\
\hline Male & 100 & $75.2 \%$ & 33 & $24.8 \%$ \\
\hline Female & 64 & $57.7 \%$ & 47 & $42.3 \%$ \\
\hline
\end{tabular}

There was no significant correlation between the workplace city of the faculty members in medical sciences universities and their health, except for levels of social function scale and overall general health levels. Chi-square test was used to examine the correlation, which is reported in the following table of frequency of the city in terms of social function levels (Table 3).

Table 3. The frequency of the city in terms of the social domain of health.

\begin{tabular}{|c|c|c|c|c|c|c|}
\hline \multirow[t]{2}{*}{ City } & \multicolumn{2}{|c|}{ Social Health } & \multirow[t]{2}{*}{ Total number per city } & \multirow[t]{2}{*}{ Chi-square value } & \multirow[t]{2}{*}{ DF } & \multirow[t]{2}{*}{ Statistical value } \\
\hline & Healthy & Sick & & & & \\
\hline Shiraz & $95(94.1 \%)$ & $6(5.9 \%)$ & 101 & \multirow{4}{*}{41.995} & \multirow{4}{*}{3} & \multirow{4}{*}{.000} \\
\hline Jahrom & $52(62.7 \%)$ & $31(37.3 \%)$ & 83 & & & \\
\hline Fasa & $19(61.3 \%)$ & $12(38.7 \%)$ & 31 & & & \\
\hline Lar and Gerash & $29(100 \%)$ & $0(0 \%)$ & 29 & & & \\
\hline
\end{tabular}

In this study, Pearson correlation test was used to investigate the relationship between physical activity and general health subscales (Table 4).

Table 4. Correlation between physical activity and health (general health and subscales)

\begin{tabular}{cccccc}
\hline Total General Health & Depression Symptoms & Social Function & $\begin{array}{c}\text { Anxiety Symptoms and } \\
\text { Sleep Disorders }\end{array}$ & Physical symptoms & Physical symptoms \\
\hline .026 & -.014 & .030 & .011 & .018 & $\mathrm{r}$ \\
\hline .683 & .830 & .646 & .858 & .774 & $\mathrm{p}$-value \\
\hline 244 & 244 & 244 & 244 & 244 & $\mathrm{~N}$ \\
\hline
\end{tabular}

The results showed that there was no significant statistical relationship between physical activity and general health subscales. Based on the test between physical activity and physical symptoms scale $(r=0.018$ and $p$-value $=0.774)$, anxiety symptoms and sleep disorders scale $(\mathrm{r}=0.011$ and $\mathrm{p}$-value $=$
$0.858)$, social function scale $(r=0.030$ and $p$ - value $=0.646)$ and depression symptoms scale $(r=-0.014$ and $\mathrm{p}$-value $=$ 0.830 ), there were no statistically significant relationships. 


\section{Discussion}

One of the major assets of an organization are the human resources. Therefore, it is important to identify and determine correctly the factors that affect the health of the organization staff.

The present study was conducted on 244 faculty members of the universities of medical sciences of Fars Province and investigated the association between physical activity and general health. No significant differences were found according to gender, results that are not consistent with Sadeghi Brojerdi, Yousefi \& Ghobadi (2007) study, where it was concluded that women's general health is poorer than men's.

The results also indicated that there was no significant statistical association between physical activity and general health. These findings are consistent with the results of Khaledan's (2000) research, which stated that participation in a variety of physical activities is likely to have a very small contribution to health. Also, the results of another study conducted by Kashef (2009) on faculty members at public universities showed that there was no significant relationship between health and physical activities. Moreover, in the study of Sharifirad, Mohebbi \& Matlabi (2007) there was no significant relationship between physical activity and general health. However, the results of many studies, such as Wu et al. (2017) and Tofighi, Babaei, Eloon Kashkuli \& Babaei (2014) showed a significant relationship between physical activity and general health. Soltani Shal, Aghamohammadian Sharbaf \& Ghanaei Chamanabad (2003) examined the effect of exercise on general health, sleep quality and quality of life of students of Mashhad University and concluded that the difference between the experimental and control groups in all the variables was statistically significant.

The main strength of the present study is the use of validated instruments. However, the results of this study should be interpreted considering its limitations. The main limitations were that physical activity and general health were self-reported and the sample size. Therefore, future studies about this topic with objective measures, larger samples and in other regions are recommended.

\section{Acknowledgments}

Hereby, the Honorable Research Assistant of Islamic Azad University, Jahrom Branch, is appreciated for the support to this project, and also all dear colleagues who contributed to this research and gave their valuable time to the researchers.

\section{References}

1. Alamdari, N. N., \& Abdi, K. (2019). The Impact of Physical Activity in the Control of Abnormal Behaviours of Iranian students. Atena Journal of Sports Sciences, 1(5), 1-11.

2. Alavi, S., Ahmadi, M., \& Zar, A. (2018). Evaluate the effectiveness of sport on job burnout, general health and life expectancy in Jahrom University of Medical Sciences staff. Community Health, 4(3), 156-165. [Persian].

3. Asci, F. (2003). The effects of physical fitness training on trait anxiety and physical self-concept of female university students. Journal of Sport and Exercise Psychology, 4(3), 255-264.

4. Baecke, J., Burema, J., \& Frijters, J. (1982). A short questionnaire for the measurement of habitual physical activity in epidemiological studies. The American Journal of Clinical Nutrition, 36(5), 936-942.

5. Bigdeli, I., \& Karam Zadeh, S. (2006). The effects of stressors on mental health nurses in Semnan. Journal of Semnan Medical Sciences Univesity, 9(1), 8-12. [Persian].

6. Brill, P. (2004). Functional fitness for older adults. Champaign (IL): Human Kinetics.

7. Brown, S., Birtwhistle, J., \& Roe L. (1999). The unhealthy lifestyle of people with schizophrenia. Psychological medicine, 29(3), 697-701.

8. Chhea, C., Warren, N., \& Manderson, L. (2010). Health worker effectiveness and retention in rural Cambodia. Rural Remote Health, 10(3), 13-21.

9. Esfahani, N. (2002). The impact of sport on physical, anxiety, sleep disorder, social function and depression components of mental health in Al Zahra University Students. Journal Harakat, 12(4), 75-86. [Persian].

10. Florindo, A., \& Latorre, M. (2003). Validation and reproducibility of the Baecke Questionnaire Assessing Habitual Physical Activity in Adult Males. Revista Brasileira de Medicina do Esporte, 9(3), 121-128.

11. Garatachea, N., Molinero, O., Martínez-García, R., Jiménez-Jiménez,
R., González-Gallego, J., \& Marquez, S. (2009). Feelings of well being in elderly people: Relationship to physical activity and physical function. Archives of Gerontology and Geriatrics, 48(3), 306-312.

12. Gillison, F., Skevington, S., Sato, A., Standage, M., \& Evangelidou, S (2009). The effects of exercise interventions on quality of life in clinical and healthy populations: A meta-analysis. Social Science \& Medicine, 68(9), 1700-1710.

13. Goldberg, D. (1988). User's Guide to the General Health Questionnaire. New York: Windsor.

14. González-Carcelén, C. M., Nicolás López, J., \& López Sánchez, G. F. (2020). Levels of physical activity in people with diabetes residing in Spain. Atena Journal of Public Health, 2(2), 1-21.

15. Hashemi Motlagh, S., \& Mozaffar, A. (2011). A comparison of communication skills and life quality between physically active and physically inactive academic staff members of Islamic Azad Universities in East Azerbaijan Province. Management Science Journal, 3(12), 7-32. [Persian].

16. Karimian, J., \& Shokrchizadeh, P. (2007). Investigating the role of physical activity in the physical, psychological and social health of the family from the point of view of Islam. Rafsanjan University of Medical Sciences Journal, 6(4), 85-88. [Persian].

17. Kashef, M. (2009). Comparison of general health, social relations and educational and research activities of active and passive faculty members of Iranian universities [PhD Thesis]. Tarbiat Moallem University, Tehran, Iran. [Persian].

18. Khaledan, A. (2000). The effect of physical activity on physiological and functional capacities of older individuals and aging. Harakat, 5, 87-108. [Persian].

19. López Sánchez, G. F., Gordon, D., Hodgson, L., Stubbs, B., Gardner, B., \& Smith, L. (2019). The effect of the 2016 Rio de Janeiro Olympics 
on spectators' physical activity. Atena Journal of Sports Sciences, 1(1), 1-8.

20. Nicolás López, J., González Carcelén, C. M., \& López Sánchez, G. F. (2020). Barriers to physical activity in people with diabetes residing in Spain. Atena Journal of Public Health, 2(3), 1-20.

21. Ramazani Negad, R., Niazi, M., \& Hemati Nezhad M. (2010). Comparing general health between people participating in sport activity and inactive people. Quarterly Journal of Sport Sciences, 2(4), 49-66. [Persian].

22. Sadeghi Brojerdi, S., Yousefi, S., \& Ghobadi, B. (2007). The relationship between general health and burnout among teachers of Physical Education in Kermanshah Province. Proceedings of the 7th National Conference on Physical Education and Sport Sciences, Tabriz University, Tabriz, Iran. [Persian].

23. Sadeghisani, M., Manshadi, F., Azimi, H., \& Montazeri, A. (2016). Validity and reliability of the Persian version of Baecke Habitual Physical Activity Questionnaire in Healthy Subjects. Asian Journal of Sports Medicine, 7(3), 44-49. [Persian].

24. Safair, S., \& Fattahzadeh, A. (2003). Global health report 2003. Tehran, Iran: The Cultural Institute of Great Ibn Sina, The Ministry of Health and Medical Education. [Persian].

25. Sánchez-Castillo, S., Cepeda-Quintanar, S., Díaz-Suárez, A., Smith, L., López-Sánchez, G. F. (2019). Actividad física en personas con EPOC residentes en España: Diferencias según sexo y edad. Journal of Sport and Health Research, 11(Supl 1), 59-68.

26. Sánchez Castillo, S., López Sánchez, G. F., Sgroi, M., Díaz Suárez, A. (2019). Body image and obesity by Stunkard's silhouettes in 14- to 21-year-old Italian adolescents. Journal of Sport and Health Research, 11(2), 199-210.

27. Sánchez García, C., Zauder, R., \& López Sánchez, G. F. (2019). Analysis of body composition and physical fitness of futsal players at school age according to their level of physical activity, diet and body image. Atena Journal of Sports Sciences, 1(4), 1-20.

28. Schmitz, N., Kruse, J., \& Kugler, J. (2004). The association between physical exercises and health-related quality of life in subjects with mental disorders: results from a cross-sectional survey. Preventive Medicine, 39(6), 1200-1207.

29. Sharifirad, G., Mohebbi, S., \& Matlabi, M. (2007). The relationship of physical activity in middle age and cardiovascular problems in old age in retired people in Isfahan. Horizon of Medical Sciences, 13(2), 57-63. [Persian].

30. Solhjoo, M. H., Afroozeh, M., Afroozeh, S., \& Kargar, N. (2011). Mental health of faculty members of physical education and other fields in Islamic Azad University. Journal of Jahrom University of Medical Sciences, 9(3), 34-38. [Persian].

31. Soltani Shal, R., Aghamohammadian Sharbaf, H., \& Ghanaei Chamanabad, A. (2003). Effect of exercise on health, quality of sleep and quality of life in Ferdowsi University of Mashhad Students. Journal of Qazvin University of Medical Sciences, 17(4), 39-46. [Persian]

32. Taghavi, M. (2001). Assessing reliability and validity of the General Health Questionnaire (GHQ). Journal of Psychology, 4, 381-398. [Persian]

33. Tofighi, A., Babaei, S., Eloon Kashkuli, F., \& Babaei, R. (2014). The relationship between the amount of physical activity and general health in Urmia Medical University Students. Journal of Urmia Nursing and Midwifery Faculty, 12(3), 166-172. [Persian].

34. Voderholzer, V., Dersch, R., Dickhut, Hu., Herter, A., Freyer, T., \& Berger M. (2011). Physical fitness in depressive patients and impact of illness course and disability. Journal of Affective Disorders, 128, 160-164.

35. Watt, D. (2003). Sports Management and Administration. London: Routledge.

36. Wu, X., Han, L., Zhang, J., Luo, S., Hu, J., \& Sun, K. (2017). The influence of physical activity, sedentary behavior on health-related quality of life among the general population of children and adolescents: A systematic review. Plos One, 12(11), e0187668.

37. Yaghubi, N. (1995). Epidemiology of mental disorders in rural and urban areas. [MS Thesis]. Iran University of Medical Sciences, Tehran, Iran. [Persian]. 